\title{
Paediatric injuries at Bugando Medical Centre in Northwestern Tanzania: a prospective review of 150 cases
}

\author{
Raymond Simon ${ }^{1 \dagger}$, Japhet M Gilyoma ${ }^{1 \dagger}$, Ramesh M Dass ${ }^{2 \dagger}$, Mabula D Mchembe $^{3 \dagger}$ and Phillipo L Chalya ${ }^{1 *}$
}

\begin{abstract}
Background: Injuries continue to be the leading cause of death and disability for children. The is a paucity of published data on paediatric injuries in our local environment. This study describes the etiological spectrum, injury characteristics and treatment outcome of paediatric injuries in our local setting and provides baseline data for establishment of prevention strategies as well as treatment guidelines.

Methods: This was a descriptive cross-sectional study involving paediatric injury patients admitted to Bugando Medical Centre from August 2011 to April 2012. Statistical data analysis was done using SPSS version 17.0 and STATA version 12.0.

Results: A total of 150 patients were studied. The age of patients ranged from 1 month to 10 years with a median age of 5 years. The male to female ratio was 2.3:1. Road traffic accident was the most common cause of injury (39.3\%) and motorcycle (71.2\%) was responsible for the majority of road traffic accidents. Only 11 (7.3\%) patients received pre-hospital care. The head /neck (32.7\%) and musculoskeletal (28.0\%) were the most frequent body region injured. Open wounds (51.4\%), foreign bodies (31.3\%) and fractures (17.3\%) were the most common type of injuries sustained. The majority of patients 84 (56.0\%) were treated surgically. Complication rate was 3.9\%. The mean duration of hospitalization was $9.7 \pm 13.1$ days. Mortality rate was $12.7 \%$. Age of the patient ( $<5$ years), late presentation and presence of complications were the main predictors of length of hospital stay $(P<0.001)$, whereas burn injuries, severe head injuries and severity of injury (Paediatric trauma score $=0-5$ ) significantly predicted mortality $(P<0.0001)$.

Conclusion: Paediatric injuries resulting from road traffic accidents (RTAs) remain a major public health problem in this part of Tanzania. Urgent preventive measures targeting at reducing the occurrence of RTAs is necessary to reduce the incidence of paediatric injuries in this region.
\end{abstract}

Keywords: Paediatric injuries, Etiological spectrum, Injury characteristics, Treatment outcome, Tanzania

\section{Background}

Trauma is reported to be an important cause of childhood morbidity, and mortality in developed countries while causing an increasing loss of life in developing countries [1]. In the United States, over 1.5 million childhood traumas occur annually, resulting in approximately 600000 hospitalizations and $15000-20000$ paediatric deaths each year [2]. In the European region, injuries account for $23 \%$ of deaths from all causes and 19\% of disability-adjusted life

\footnotetext{
* Correspondence: drphillipoleo@yahoo.com

${ }^{\dagger}$ Equal contributors

'Department of Surgery, Catholic University of Health and Allied Sciences Bugando, Mwanza, Tanzania

Full list of author information is available at the end of the article
}

years (DALYs) from all causes in the age group 0-19 years [3]. In Africa, the true incidence is not known but injuries have been estimated to account for $13 \%$ of childhood disease burden and nearly 1 million deaths occur per year in developing countries, including Africa $[4,5]$.

In Tanzania, like other developing countries, injuries constitute a major but neglected public health problem and yet have a significant adverse effect on the country's economy and health services in terms of morbidity, mortality and long term disability among paediatric population [6]. Paediatric injuries are a single commonest cause of paediatric surgical admissions at Bugando Medical Centre and contribute significantly to high morbidity and mortality.

\section{Ciomed Central}

(c) 2013 Simon et al.; licensee BioMed Central Ltd. This is an open access article distributed under the terms of the Creative Commons Attribution License (http://creativecommons.org/licenses/by/2.0), which permits unrestricted use, distribution, and reproduction in any medium, provided the original work is properly cited. 
With increasing motorization and criminal activities in both urban and semi-urban communities of developing countries, the incidence of traumatic injuries in children is on the increase [7]. Children aged 10 years and below are particularly at risks for injuries because they are unable to recognize and avoid many potential risks for injuries due to their low level of judgment exposing them to great danger of accidents $[7,8]$.

The causes and pattern of paediatric injuries have been reported to vary according to geographic area, socioeconomic status and environment factors [9]. The purpose of studying injury characteristics and its causes is to establish programmes to prevent and control its development and spread $[7,10]$.

It has been shown that improved hospital care results in lower mortality and that care is best delivered at a paediatric trauma centre [11]. Therefore the identification of high-risk injury patterns may lead to improved care and ultimately further improvements in outcome in children admitted to hospital with trauma [12].

Since the majority of paediatric injuries are preventable, a clearer understanding of the causes, injury patterns and outcome of these patients is essential for establishment of prevention strategies as well as treatment protocols $[7,13]$.

There is paucity of data on paediatric injuries in Tanzania and the study setting in particular. Such information is necessary for assessing the impact of trauma on child health and for setting priorities to improve paediatric trauma care. The aim of this study was to outline the etiological spectrum, injury characteristics and outcome of paediatric injuries and to identify the predictors of the outcome of these patients in our setting. The study results will provide basis for planning of prevention strategies and establishment of treatment protocols.

\section{Methods}

\section{Study design and setting}

This was a descriptive prospective study involving paediatric injury patients admitted to Bugando Medical Centre (BMC) over a nine-month period from August 2011 to April 2012 inclusive.

The study was conducted at the A \& E department of Bugando Medical Centre. BMC is one of the four largest referral hospitals in the country and it is located in Mwanza city in the northwestern part of Tanzania. It has a bed capacity of 1000 and serves as a referral centre for tertiary specialist care for a catchment population of approximately 13 million people from Mwanza, Mara, Kagera, Shinyanga, Tabora and Kigoma. It is also a consultancy and teaching hospital for the Catholic University of Health and Allied Sciences-Bugando (CUHAS-Bugando) and other paramedics. Paediatric injury patients are first seen at the A \& E department where the surgical team does primary and secondary surveys according to advanced trauma life support (ATLS). From the A \& E department these patients are either discharged home or admitted in pediatric surgical wards after definitive treatment either in operating theatre or at the A \& E department. Depending on the severity of injury, patients may also be admitted to the intensive care unit (ICU).

\section{Study subjects (patients)}

The study included all pediatric injury patients aged 10 years and below presenting to the $\mathrm{A} \& \mathrm{E}$ department and paediatric surgical ward of BMC during the study period. Patients without next of kin to consent for the study and those who died before complete assessment were excluded from the study. Convenience sampling of patients who met the inclusion criteria was performed until the sample size is reached. Recruitment of patient to participate in the study was done at the A \& E department after primary and secondary surveys done by the admitting surgical team. Patients were screened for inclusion criteria and those who met the inclusion criteria were offered explanations about the study and requested to consent before being enrolled into the study. All recruited patients were first resuscitated in the A \& E department according to the Advanced.

Trauma Life Support (ATLS) principles and were then taken into the paediatric surgical ward or the intensive care unit (ICU) from where necessary investigations were completed and further treatment was instituted.

The severity of injury was determined using the Paediatric trauma score (PTS) [14]. Severe injury consisted of a PTS $0-5$, moderate injury 6-8, and mild injury 9-12. Patients with head injuries were classified according to Glasgow Coma Scale (GCS) into: severe (GCS 3-8), moderate (GCS 9-12) and mild (GCS 13-15). Depending on the type of injury, the patients were treated either conservatively or by surgery.

Patients were followed up till discharge or death. Data were collected using a pre-tested coded questionnaire. Data administered in the questionnaire included; demographic characteristics (e.g. age, sex), circumstances of injury, characteristics of injury, treatment modalities, Length of Hospital Stay (LOS) and mortality.

\section{Statistical data analysis}

Statistical data analysis was done using SPSS software version 17.0 and STATA version 12.0. Data were summarized in form of proportions, frequent tables, bar and pie charts for categorical variables. Means, median, mode, standard deviation and histograms were used to summarize continuous variables. Chi-square test was used to test for significance of associations between the predictor and outcome variables in the categorical variables. Student t-test was used to test for significance of associations between the predictor and outcome variables in the 
continuous variables. Significance was defined as a p-value of less than 0.05. Multivariate logistic regression analysis was used to determine predictor variables that are associated with outcome.

\section{Ethical consideration}

Ethical approval to conduct the study was obtained from the CUHAS-Bugando/BMC joint institutional ethic review committee before the commencement of the study. Informed consent was sought from each patient's next of kin/parents before being enrolled into the study.

\section{Results}

\section{Patient's characteristics}

During the period under review, a total of 160 paediatric injury patients were admitted to the paediatric surgical ward. Of these, 10 patients were excluded from the study due to failure to meet the inclusion criteria. Thus, 150 patients were studied (Figure 1). The age of patients ranged from 1 month to 10 years with a median of 5 years. The peak age incidence was 6-8 years. One hundred and four (69.3\%) were males and $46(30.7 \%)$ were females. the male to female ratio of 2.3: 1 with a male predominance in each age group. In this study, no patient had premorbid illness.

\section{Circumstances of injury}

Regarding the time of injury, 125 (83.3\%) patients sustained injury during the day, $22(14.7 \%)$ at night and in $3(2.0 \%)$, the time was not specified. Most of injuries occurred at home (57.3\%) as shown in Table 1. All patients in this study sustained unintentional injuries. Road traffic accident was the most common cause of injury accounting for $39.3 \%$ of cases (Table 1). Motorcycle $(42,71.2 \%)$ was responsible for the majority of road traffic accidents, followed by motor-vehicles in $17(28.8 \%)$ patients. Pedestrians $(50,84.7 \%)$ accounted for the majority of victims, followed by passengers $(9,15.3 \%)$. Most patients $(118,78.7 \%)$ in this study sustained blunt injuries. Other mechanisms of injury included burn and foreign body inhalation/ingestion in $32(21.3 \%)$ and $47(31.3 \%)$ patients respectively. The vast majority of patients $(126,84.0 \%)$ reported to the A \& E department within 24 hours after injury.

In this study, only $11(7.3 \%)$ patients received prehospital care. The majority of $(111,74.0 \%)$ were brought in by relatives/friends or Good Samaritans. 32 (21.3\%) were brought in by ambulance and 7 (4.7\%) were brought in by police. The means of transport from the site of injury to hospital in the majority of patients was private transport in $80(72.1 \%)$, public transport in $24(21.6 \%)$ and motorcycle in 7 (6.3\%) patients.

The majority of patients $(125,83.3 \%)$ were attended to within 6 hours of arrival to the A \& E department as shown in Table 1.

\section{Injury characteristics}

The head/neck and musculoskeletal (extremities) were the most frequent body region injured accounting for $32.7 \%$ and $28.0 \%$ of cases respectively (Table 1 ). Isolated injuries occurred in 116 (77.3\%) patients while 34 (22.7\%) patients had multiple injuries. Open wounds (i.e. bruises, abrasions, lacerations, cut wounds, burn wounds etc.), foreign bodies and fractures were the most common type of injuries sustained (Table 2). In patients with burn injuries, scald was the most common type of burn in 24 (84.4\%) patients followed by flame burn in $5(15.6 \%)$ patients. There was no chemical, electrical or radiation burns. The \% TBSA among burn injury patients ranged from 5-50\% with a median of $14.0 \%$.

According to Paediatric Trauma Score (KTS), the majority of patients sustained mild injuries (PTS $=9-12$ ) in $85(56.7 \%)$ patients. Moderate injuries (PTS $=6-8$ ) and severe injuries (PTS $=0-5)$ were recorded in $60(40.0 \%)$

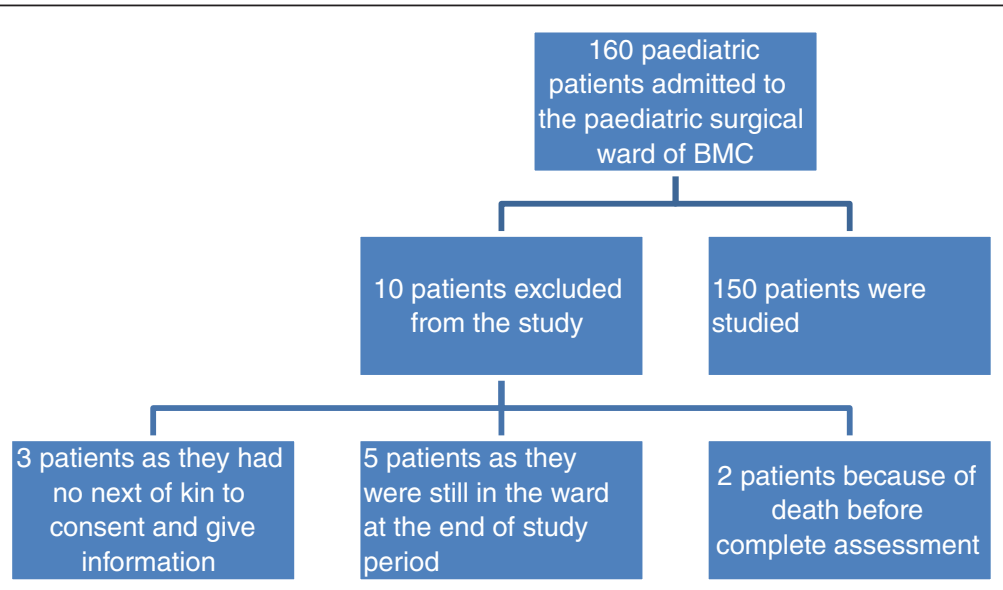

Figure 1 Flow chart of patients showing number of patients. Keys: $B M C=$ Bugando Medical Centre. 
Table 1 Distribution of patients according to the circumstances and characteristic of injury

\begin{tabular}{|c|c|c|}
\hline Variables & Number of patients & Percentage \\
\hline \multicolumn{3}{|l|}{ Time of injury } \\
\hline Day & 125 & 83.3 \\
\hline Night & 22 & 14.7 \\
\hline Time not specified & 3 & 2.0 \\
\hline \multicolumn{3}{|l|}{ Place of injury } \\
\hline Home & 86 & 57.3 \\
\hline Sideway/along road & 59 & 39.3 \\
\hline Recreation & 3 & 2.0 \\
\hline School & 2 & 1.3 \\
\hline \multicolumn{3}{|l|}{ Nature of injury } \\
\hline Intentional & 0 & 0 \\
\hline Unintentional & 150 & 100 \\
\hline \multicolumn{3}{|l|}{ Cause of injury } \\
\hline RTA & 59 & 39.3 \\
\hline Falls & 12 & 8 \\
\hline Burn & 32 & 21.3 \\
\hline Foreign body & 47 & 31.3 \\
\hline \multicolumn{3}{|l|}{ Mechanism of injury } \\
\hline Blunt & 71 & 47.3 \\
\hline Burn & 32 & 21.3 \\
\hline Foreign body ingestion & 47 & 31.3 \\
\hline \multicolumn{3}{|l|}{ Arrival time } \\
\hline$\leq 24 \mathrm{hrs}$ & 124 & 83 \\
\hline$>24 \mathrm{hrs}$ & 26 & 17 \\
\hline \multicolumn{3}{|l|}{ Pre hospital care } \\
\hline Done & 11 & 7.3 \\
\hline Not done & 139 & 92.7 \\
\hline \multicolumn{3}{|l|}{ Waiting time } \\
\hline$\leq 6 \mathrm{hrs}$ & 125 & 83.3 \\
\hline $6-24 \mathrm{hrs}$ & 24 & 16.0 \\
\hline$>24 \mathrm{hrs}$ & 1 & 0.67 \\
\hline \multicolumn{3}{|l|}{ Body region affected } \\
\hline Head/neck & 49 & 32.7 \\
\hline Chest & 20 & 13.3 \\
\hline Abdomen/pelvic & 5 & 3.3 \\
\hline Extremities & 42 & 28.0 \\
\hline Multiple body part & 34 & 22.7 \\
\hline
\end{tabular}

and $5(3.3 \%)$ patients respectively. The PTS ranged from 5 to12 with a median of 9.0. The Glasgow coma scale indicated that most of the patients $(15,51.7 \%)$ sustained moderate head injury, $8(27.6 \%)$ patients sustained severe head injury and $6(20.7 \%)$ patients had mild head injury.
Table 2 Distribution of patients according to the type of injury

\begin{tabular}{lll}
\hline Type of injury & Frequency & Percentage \\
\hline Bruises & 45 & 30.0 \\
Laceration & 9 & 6.0 \\
Cut wounds & 12 & 8.0 \\
Burn wounds & 32 & 21.3 \\
Fractures & 26 & 17.3 \\
Sprain & 13 & 8.7 \\
Dislocation & 9 & 6.0 \\
Foreign bodies & 47 & 31.3 \\
\hline
\end{tabular}

\section{Admission pattern and treatment modalities}

A total of 140 (93.3\%) patients were admitted in the paediatric surgical wards and the remaining 10 (6.7\%) patients were admitted to the intensive care unit (ICU). The majority of patients 84 (56.0\%) were treated surgically as shown in Table 3.

\section{Treatment outcome}

Five patients developed complications giving a complication rate of $3.9 \%$. Wound sepsis was the most common complications in $3(2.0 \%)$ patients followed by post-burn contracture and pneumonia in $1(0.7 \%)$ patient each respectively. The overall LOS ranged from 1 to 72 days with a mean and median of $9.7 \pm 13.1$ days and 4.0 days respectively. The mode was 2.0 days. The LOS for nonsurvivors ranged from 1 day to 16 days with a mean of $2.6 \pm 6.3$ days. The median and the mode were 1.0 day each respectively.

Table 4 shows predictors of LOS according to univariate analysis and multivariate logistic regression analysis. In this study, nineteen patients died giving a mortality rate of $12.7 \%$. Table 5 shows predictors of mortality according to univariate analysis and multivariate logistic regression analysis.

Table 3 Distribution of patients according to surgical procedure performed

\begin{tabular}{lll}
\hline Surgical procedure performed & Frequency & Percentage \\
\hline Wound debridement & 21 & 14.0 \\
Treatment of fractures & 26 & 17.3 \\
Bronchoscopy \pm foreign body removal & 14 & 9.3 \\
Esophagoscopy \pm foreign body removal & 32 & 21.3 \\
Skin grafting & 5 & 3.3 \\
Amputation & 2 & 1.3 \\
Craniotomy & 2 & 1.3 \\
Margil's foreign body removal & 1 & 0.7 \\
\hline
\end{tabular}


Table 4 Predictors of LOS according to univariate analysis and multivariate logistic regression analysis

\begin{tabular}{|c|c|c|c|c|c|c|}
\hline \multirow[t]{2}{*}{ Independent variables } & \multicolumn{4}{|c|}{ Univariate analysis } & \multicolumn{2}{|c|}{ Multivariate analysis } \\
\hline & $\leq 14$ days & $>14$ days & OR $[95 \% \mathrm{Cl}]$ & P -Value & OR $95 \% \mathrm{Cl}$ & P -Value \\
\hline \multicolumn{7}{|l|}{ Age group } \\
\hline$<5 \mathrm{yrs}$ & $44(62.9)$ & $26(37.1)$ & $3.3[1.5-7.3]$ & 0.002 & $3.9[1.60-9.4]$ & 0.003 \\
\hline $5-10 y r s$ & $68(85)$ & $12(15)$ & 1 & & & \\
\hline \multicolumn{7}{|l|}{ Sex } \\
\hline M & $77(74.0)$ & $27(26.0)$ & 1 & & & \\
\hline $\mathrm{F}$ & $35(76.1)$ & $11(23.9)$ & $0.9[0.4-2.0]$ & 0.790 & & \\
\hline \multicolumn{7}{|l|}{ Injury arrival time } \\
\hline$\leq 24 \mathrm{hrs}$ & $93(73.8)$ & $33(26.2)$ & 1 & & $0.2[0.04-0.91]$ & 0.037 \\
\hline$>24 \mathrm{hrs}$ & $19(79.2)$ & $5(20.8)$ & $0.7[0.26-2.15]$ & 0.581 & & \\
\hline \multicolumn{7}{|l|}{ Pre hosp care } \\
\hline Done & $6(54.6)$ & $5(45.5)$ & 1 & & & \\
\hline Not done & $106(76.3)$ & $33(23.7)$ & $0.4[0.11-1.3]$ & 0.122 & & \\
\hline \multicolumn{7}{|l|}{ Mech injury } \\
\hline Blunt & $101(85.6)$ & $17(14.4)$ & 1 & & & \\
\hline Burn & $11(34.4)$ & $21(65.6)$ & $11.3[4.6-27.7]$ & $<0.001$ & & \\
\hline \multicolumn{7}{|l|}{ Wait time } \\
\hline$<6$ hrs & $93(74.4)$ & $32(25.6)$ & 1 & & & \\
\hline$\geq 6$ & 19(76.0) & $6(24.0)$ & $0.9[0.34-2.5]$ & 0.867 & & \\
\hline \multicolumn{7}{|l|}{ PTS } \\
\hline Mild & $70(82.3)$ & $15(17.7)$ & 1 & & & \\
\hline Mode/severe & $42(64.6)$ & $23(35.4)$ & $2.6[1.2-5.4]$ & 0.015 & & \\
\hline \multicolumn{7}{|l|}{ Complications } \\
\hline Yes & $1(20.0)$ & $4(80.0)$ & 1 & & & \\
\hline No & $92(74.8)$ & $31(25.2)$ & $0.5[0.2-0.8]$ & 0.008 & $1.5[1.2-6.4]$ & 0.014 \\
\hline
\end{tabular}

\section{Discussion}

\section{Patient's characteristics}

Children have a unique profile of risks for injuries because they are unable to recognize and avoid many potential risks on their own $[15,16]$. In this study, the peak age incidence was 6-8 years which is in agreement with other studies done elsewhere $[17,18]$. High incidence of injuries in this age group reflects lack of coordination and unawareness of dangerous substances. In addition, this is the schoolage group and is usually involved in road traffic accidents as they rush through heavy traffic to and from their schools. These school-age group children are usually very active and are often less supervised than pre-school age children. This observation calls for an improved school transportation system.

In our study, males were more affected than females with a male to female ratio of $2.3: 1$ which is in agreement with other studies [19]. The reasons for the male preponderance in our study may be attributed to the overactive nature of male children as compared to the females.
The presence of pre-existing illness has been reported to have an impact on the outcome of paediatric injury patients [20]. In the present study, no patient had pre-existing illness.

\section{Circumstances of injury}

With regard to the time injury, most of injuries in the present study occurred during the day which is in agreement with that of other studies $[17,21]$. Increased rate of injuries during the day can be explained by increased traffic jams as well as increased human activities in the city during the day time. Knowing the time of injury in trauma patient is important for prevention strategies.

The majority of paediatric injury in this study occurred at home, which is in agreement with other studies done elsewhere $[21,22]$. This finding is at variant with an Iranian study which reported streets as the most common place of occurrence of paediatric injuries [17]. The finding that most of paediatric injuries occurred at home demonstrates the important role of parental supervision as a key factor in child safety. 
Table 5 Predictors of mortality according to univariate analysis and multivariate logistic regression analysis

\begin{tabular}{|c|c|c|c|c|c|c|}
\hline \multirow[t]{2}{*}{ Independent variables } & \multirow{2}{*}{$\begin{array}{l}\text { Alive } \\
\mathrm{N}=131\end{array}$} & \multirow{2}{*}{$\begin{array}{l}\text { Dead } \\
N=19\end{array}$} & \multirow{2}{*}{$\begin{array}{l}\text { Univariate analysis } \\
\text { OR }(95 \% \mathrm{Cl}\end{array}$} & \multirow[b]{2}{*}{$P$-value } & \multicolumn{2}{|c|}{ Multivariate analysis } \\
\hline & & & & & OR $(95 \% \mathrm{Cl})$ & P- Value \\
\hline \multicolumn{7}{|l|}{ Age group } \\
\hline$\leq 5$ & $63(90)$ & $7(10)$ & 1 & & & \\
\hline 5- 10 & $68(85)$ & $12(15)$ & $1.6[0.6-4.3]$ & 0.361 & & \\
\hline \multicolumn{7}{|l|}{ Sex } \\
\hline M & $93(89.4)$ & $11(10.6)$ & 1 & & & \\
\hline $\mathrm{F}$ & $38(82.6)$ & $8(17.4)$ & $1.8[0.7-4.8]$ & 0.252 & & \\
\hline \multicolumn{7}{|l|}{ Arriving time } \\
\hline$\leq 24 \mathrm{hrs}$ & 112(88.9) & 14(11.1) & 1 & & & \\
\hline$>24 \mathrm{hrs}$ & 19(79.2) & $5(20.8)$ & $2.1[0.7-6.5]$ & 0.197 & & \\
\hline \multicolumn{7}{|l|}{ Prehospital care } \\
\hline Not done & 124(89.2) & $15(10.8)$ & 1 & & & \\
\hline Done & $7(63.6)$ & $4(36.4)$ & $4.7[1.2-18.0]$ & 0.023 & & \\
\hline \multicolumn{7}{|l|}{ Mechanism of injury } \\
\hline Blunt & 108(91.5) & $10(8.5)$ & 1 & & & \\
\hline Burn & 23(71.9) & $9(28.1)$ & $4.2[1.5-11.6]$ & 0.005 & $38.8[2-750.9]$ & 0.016 \\
\hline \multicolumn{7}{|l|}{ Waiting time } \\
\hline$\leq 6 \mathrm{hrs}$ & 107(85.6) & $18(14.4)$ & 1 & & & \\
\hline$>6 \mathrm{hrs}$ & $24(96)$ & $1(4.0)$ & $0.25[0.3-1.9]$ & 0.185 & & \\
\hline \multicolumn{7}{|l|}{ Affected part } \\
\hline Trunk/extremities & $66(98.5)$ & $1(1.5)$ & 1 & & & \\
\hline Head & 40(81.6) & $9(18.4)$ & $14.6[1.8-121.6]$ & 0.012 & $284[12.3-6592.6]$ & 0.000 \\
\hline Multiple & $25(73.5)$ & $9(26.50$ & $23.8[2.7-197.3]$ & 0.003 & $27[2.6-285.1]$ & 0.006 \\
\hline \multicolumn{7}{|l|}{ PTS } \\
\hline Mild & 83(97.6) & $2(2.4)$ & 1 & & & \\
\hline Moderate/severe & 48(73.8) & $17(26.2)$ & $7.2[3.6-11.8]$ & 0.012 & $3.9[3.1-5.9]$ & 0.000 \\
\hline \multicolumn{7}{|l|}{ GCS } \\
\hline Mild & $117(96.7)$ & $4(3.3)$ & 1 & & & \\
\hline Moderate/severe & $14(48.3)$ & $15(51.7)$ & $2.6[1.4-9.9]$ & 0.022 & $3.8[2.5-34.4]$ & 0.003 \\
\hline
\end{tabular}

In this study, all paediatric injury patients sustained unintentional injuries resulting from road traffic accidents, falls, burns and foreign body inhalation/ingestion. There were no cases of intentional injuries. However, the lack of intentional injuries in our study may actually be an underestimate and the magnitude of the problem may not be apparent because many cases are not reported for fear of been arrested by police. Therefore, paediatric forensic examination should be performed if a child is likely to suffer from abuse, neglect or intentional injury.

Road traffic accidents have been reported to be the commonest cause of blunt paediatric injuries in most studies as supported by the present study [23]. In contrast to our findings, a study in Malawi reported fall from height as the most common cause of paediatric injuries [24]. A study in Kenya reported that burn injuries as the most frequent cause of paediatric injuries [18]. High incidence of road traffic accidents in our study may be attributed to recklessness and negligence of the driver, poor maintenance of vehicles, driving under the influence of alcohol or drugs and complete disregard of traffic laws. Improvement in road conditions, prevention of overloading of commuter vehicles, maintenance of vehicles and encouraging enforcement of traffic laws will decrease the frequency and extent of these injuries. In agreement with other studies [25,26], motorcycle $(71.2 \%)$ was responsible for the majority of road traffic accidents. The prevalence of motorcycle injuries in this study is higher than that reported previously at the same centre by Chalya et al. [26] reflecting increase in the magnitude of the problem in our setting. Motorcycle use is becoming popular in Tanzania as it has become a cheaper and easier means of transportation in most cities. However their use is characterized by non-helmet use by riders and their passengers, passenger 
overload, lack of certified driver training and valid licensing, over speed and reckless driving, poor regulation and law enforcement and possible use of alcohol and drugs. In this study, pedestrians $(84.7 \%)$ accounted for the majority of road traffic victims, which is in keeping with other study done elsewhere [17]. High incidence of pedestrians among children has been attributed to their developmental and behavior limitations in complex traffic situations $[10,11]$. Pedestrians aged 10 years and below are particularly vulnerable because of their small physical size and underdeveloped abilities to dealing with traffic situations, both cognitive (attention focus, interpreting signs) and perceptual (locating sounds, judging speed, peripheral vision) [11]. Children under the age of 10 years do not have the ability to cross roads without adult help.

Injuries related to foreign bodies in the aerodigestive tract was the second most common cause of paediatric injuries in our locality as previously reported by Gilyoma and Chalya [27] at the same centre. In agreement with other studies [27-29], our study found that foreign bodies in the esophagus was more prevalent than in the bronchus, ear or nose. In this study, we could not establish the reason for this anatomical distribution. Several factors contribute to high incidence of aerodigestive tract foreign bodies in this age group including social factors (e.g. carelessness of parents, children's habit of putting objects in their mouth, crying/playing during eating) and anatomical factors (e.g. absent of molar teeth, inadequate control of deglutition) have been mentioned in literature [30,31].

The prehospital care of injured paediatric patients is the most important factor in determining the ultimate outcome after injury [12]. In our study, only $7.3 \%$ of patients had pre-hospital care. The lack of advanced pre-hospital care in most developing countries like Tanzania and ineffective ambulance system for transportation of patients to hospitals are a major challenges in providing care for paediatric injury patients in these countries and have contributed significantly to poor outcome of these patients due to delay in definitive treatment.

The majority of patients in our study reported to the A \& E department within 24 hours of injury, which is in keeping with other reports $[17,21]$. Our experience shows that early presentation is common with very young children, and when there are more serious symptoms of severe injury, thus compelling the frightened patients or parents to seek medical attention. Late presentation is more common in asymptomatic and mild cases. Gilyoma and Chalya [27] in their experiences with endoscopic procedures for removal of foreign bodies of the aerodigestive tract at Bugando Medical Centre found that the majority of patients mainly children presented to the A \& E department within 24 hours of inhalation/ingestion of foreign.

Waiting time in emergency departments may be attributable to many factors and may stretch up to three hours before completion of all necessary procedures, even in developed countries [32]. This study found that the majority of the patients $(83.3 \%)$ were attended to within 6 hours of arrival at the A \& E Department. Lambe et al. [33] reported a lower mean waiting time of 56 minutes in California, USA. Review of emergency department administration has been demonstrated to improve efficiency in care delivery [34]. A waiting time of 30 minutes for a general outpatient clinic is considered reasonable but should be even shorter for emergency visits [35].

\section{Injury characteristics}

In agreement with previous studies $[17,18]$, the present study found that the head and the musculoskeletal (extremities) were the most common body region injured and the former accounted for most of the deaths and admission to intensive care. Higher incidence of head injuries in most previous studies as well as our study may be attributed to the disproportionately large head and weak neck musculature in children that puts them at particular risk for contre-coup brain injuries even at low velocity injury [21]. Our high figure of musculoskeletal injuries affecting mainly the lower limbs is attributable to the large number of pedestrians. Pedestrians are unprotected road users and therefore they are highly exposed to high risk of limb injuries [36].

The type of injuries in this study is comparable with what is reported in other studies $[17,21,36]$. In the present study, open wounds (i.e. bruises, abrasions, lacerations, cut wounds, burn wounds etc.), foreign bodies and fractures were the most common type of injuries sustained.

A number of scoring systems have been developed to facilitate consistent trauma triage, severity evaluation, management and prognostication [37]. Paediatric Trauma Score (PTS) is one of trauma scores designed to accurately assess injury severity and extent of injury, aid with the prediction of survival and subsequent morbidity [38]. The PTS was devised specifically for the triage of paediatric trauma patients [14]. The PTS is calculated as the sum of individual scores from six clinical variables including weight, airway, systolic blood pressure (SBP), central nervous system (CNS) status (level of consciousness), presence of an open wound, and skeletal injuries $[39,40]$. According to Paediatric Trauma Score (PTS), the majority of patients in this study sustained mild injuries accounting for $56.7 \%$ of cases. The Glasgow coma scale (GCS) was developed as a means of assessing a patient's level of consciousness by assigning coded values for three behavioral responses $[14,39,40]$. In this study, the GCS indicated that most of the patients sustained moderate head injury.

\section{Treatment modalities}

Most of our patients were treated surgically, which is in agreement with other similar studies [41,42]. The high 
incidence of surgical treatment in our study is attributable to the high incidence of injuries that required surgical intervention. In this study, endoscopic removal of aerodigestive foreign bodies, treatment of fractures and wound debridement were the most frequent surgical procedure performed. Regarding endoscopic removal of aerodigestive foreign bodies, oesophagoscopy for removal of foreign bodies was the most common procedure performed as reported earlier by Gilyoma and Chalya [27].

\section{Treatment outcome}

The presence of complications has an impact on the final outcome of patients presenting with paediatric injuries as supported by the present study [43,44]. The pattern of complications in the present study is similar to what was reported by others $[17,23,36]$. Early recognition and management of complications following paediatric injury is of paramount in reducing the morbidity and mortality resulting from this form of trauma.

The length of hospital stay (LOS) has been reported to be an important measure of morbidity among trauma patients and has an impact on patient's final outcome $[43,44]$. Prolonged duration of hospital stay is associated with unacceptable burden on hospital resources as well as on increased costs of health care [45]. In the present study, the overall average LOS in the present study was higher than that reported by others $[3,21]$. The reasons for prolonged LOS in our study according to multivariate logistic regression analysis included young patient's age, delayed presentation and presence of complications.

The current study had a mortality rate of $12.7 \%$, which is higher than that reported by others [46-48]. Factors responsible for high mortality in our study included burn injuries, severe head injuries, severe injuries and multiple injuries. Addressing these factors responsible for high mortality in our patients is mandatory to be able to reduce mortality associated with these injuries.

\section{Conclusion}

Paediatric injuries resulting from road traffic accidents (RTAs) remain a major public health problem and contribute a substantial proportion of all paediatric surgical admissions at Bugando Medical Centre. Most of injuries occurred at home and sideways/along roads. Head and musculoskeletal injuries were the most common body region injured predisposing these patients to prolonged hospitalization and mortality. Open wounds (i.e. bruises, abrasions, lacerations, cut wounds, burn wounds etc.), foreign bodies and fractures were the most common type of injuries sustained. It is therefore recommended that:-

- Urgent preventive measures targeting at reducing the occurrence of RTAs is necessary to reduce the incidence of paediatric injuries in this region.
- The finding that most of paediatric injuries occurred at home and sideways/along roads calls for a need for educational and intervention programmes to increase the awareness and understanding of child safety and injury prevention in our local setting and to make the home a safe environment for children.

- Advanced pre-hospital care and effective ambulance system for transportation of patient to hospital is highly needed in our setting in order to improve the outcome of these patients.

- Early presentation to the hospital for early diagnosis and definitive treatment following these injuries is highly recommended to reduce the morbidity and mortality resulting from such injuries.

\section{Competing interests}

The authors declare that they have no competing interests.

\section{Authors' contributions}

RS-Study design, data analysis, manuscript writing \& editing, JMG, RMD MDM participated in data analysis, manuscript writing \& editing and PLC participated in data analysis, manuscript writing, final editing and submission of the manuscript. All authors read and approved the final manuscript.

\section{Acknowledgements}

The authors would like to thank the members of staff of Surgical Department for their invaluable contributions in the preparation of this manuscript.

\section{Author details}

'Department of Surgery, Catholic University of Health and Allied Sciences Bugando, Mwanza, Tanzania. ${ }^{2}$ Department of Orthopaedic \& Trauma, Catholic University of Health and Allied Sciences - Bugando, Mwanza, Tanzania. ${ }^{3}$ Department of Surgery, Muhimbili University of Health and Allied Sciences, Dar Es Salaam, Tanzania.

Received: 19 May 2012 Accepted: 8 November 2013

Published: 13 November 2013

\section{References}

1. Katherine $K$, Anne MW, Harold S, Jeffrey CG: Is a complete trauma series indicated for all paediatric trauma victims? Paediatr Emerg Care 2002, 18:75-77.

2. Guyer B, Freedman MA, Strobino DM, Sondik EJ: Annual summary of vital statistics: trends in health of Americans during the 20th Century. Pediatr 2000, 106(6):1307-1317.

3. Osinaike B, Amanor-Boadu S: Paediatric trauma admissions in a Nigerian ICU. Internet J Emerg Intensive Care Med 2006, 9:2.

4. Deen JL, Vos T, Huttley SRA: Injuries and non-communicable diseases: emerging health problems of children in developing countries. Bull World Health Organ 1999, 77:518-524.

5. Murray CJL, Lopez AD: Global and regional cause-of-death pattern in 1999. Bull World Health Organ 1994, 72:447-448.

6. Museru LM, Leshabari MT, Mbembati NAA: Patterns of road traffic injuries and associated factors among school age children in Dar-es-Salaam, Tanzania. African safety promotion. J Inj Violence Prev 2002, 1(1):37-41.

7. Maria HP, Kurt DN, Martin RE, et al: Patterns of injury in children. $J$ Pediatr Surg 1990, 25(1):85-91.

8. Cross DS, Hall M: Child pedestrian safety: the role of behavioral science. Med J Aust 2005, 182(7):318-319.

9. Oyedeji GA, Oyedeji AO: Causes pattern and outcomes of severe injuries in children. A hospital based study. NJP 2003, 30:86-92.

10. Abantanga FA, Mock CN: Childhood injuries in an urban area of Ghana a hospital-based study of 677 cases. Pediatr Surg Int 1998, 13:515-518.

11. Roberts I, Campbell F, Hollis S, Yates D: Reducing accident death rates in children and young adults: the contribution of hospital care. BMJ 1996, 313:1239-1241. 
12. Densmore JC, Lim HJ, Oldham KT, Guice KS: Outcomes and delivery of care in pediatric injury. J Pediatr Surg 2006, 41:92-98.

13. Alicoglu B, Yalniz E, Eskin D, Yilmaz B: Injuries associated with motorcycle accidents. Acta Orthop Traumatol Turc 2008, 42(2):106-111.

14. Gilbert JC, Arbesman MC: Pediatric injury scoring and triage methodology. In Operative pediatric surgery. Edited by Ziegler MM, Azizkhan RG, Weber TR. McGraw- Hill professional; 2003:1084-1095.

15. Adensunkanmi AR, Oginni LM, Oyelami AO: Epidemiology of childhood injury. J Trauma Inj Infect Crit Care 1998, 4:506-511.

16. Gediu E: Accidental injuries among children in Northwestern Ethiopia. East Afr med J 1994, 71:807-810.

17. Karbakhsh M, Zargar M, Zarei MR, Khaji A: Childhood injuries in Tehran: a review of 1281 cases. Turkish J Paed 2008, 50:317-325.

18. Gome DL, Mutiso VM, Kimende K: Paediatric trauma at KNH, Nairobi Kenya East Centr Afr. J Surg 2005, 10(2):33-36

19. Chapp-Jumbo AU, Adisa AC: Pattern of trauma among paediatric in- patients-The Abia State University teaching hospital experience. Eur J Sci Res 2009, 29(3):411-414.

20. Kirsch TD, Beaudreau RW, Holder YA, Smith GS: Pediatric injuries presenting to an emergency department in developing country. Pediatr Emerg Care 1996, 12:441-445.

21. Al Kilani HHY, Al Mosheh AW, Khalid MK, el Tawil MS, Ibrahim TK: Paediatric trauma: a hospital based study of pattern of childhood injuries in the State of Qatar. Middle East J Emerg Med 2001, 1(1):18-22.

22. Mungadi IA, Abubakar U: Pattern of Padiatric trauma in North Westrn Nigeria. Sahel Med J 2004, 791:32-35.

23. Odero W, Ganer P, Zwi A: Road traffic injuries in developing countries: a comprehensive review of epidemiological studies. Trop Med Int Health 1997, 2:445-460.

24. Simmons D: Accidents in Malawi. Arch Dis Child 1985, 60:64.

25. Chalya PL, Mabula JB, Ngayomela IH, Kanumba ES, Chandika AB, Giiti G, Mawalla B, Balumuka DD: Motorcycle injuries as an emerging public health problem in Mwanza City, north- western Tanzania. Tanzan J Health Res 2010, 12:214-221.

26. Chalya PL, Mabula JB, Dass RM, Mbelenge N, Ngayomela IH, Chandika AB, Gilyoma JM: Injury characteristics and outcome of road traffic crash victims at Bugando Medical Centre in Northwestern Tanzania. J Trauma Manag Outcomes 2012, 6:1

27. Gilyoma JM, Chalya PL: Endoscopic procedures for removal of foreign bodies of the aerodigestive tract, Bugando Medical Centre experience. BMC Ear Nose Throat Disorder 2011, 21(11):2.

28. Uba AF, Adeyemo AO, Adejuyigbe O: Management of esophageal foreign in children. East Afr Med J 2002, 79(6):334-338.

29. Diaz GA, Valledo L, Seda F: Foreign bodies from upper aerodigestive tract of children in Puerto Rico. Bol Assoc Med PR 2000, 92(9-12):124-129.

30. Schmidt $H$, Manegold BC: Foreign body aspiration in children. Surg EndosC 2000, 14(7):644-648

31. MucGuirt WF, Holmes KD, Feelis R: Tracheobronchial foreign bodies. Laryngoscope 1988, 98(6 Pt 1):615-618.

32. Havili JH, van Alphen S, Fairweather S, Van derpyl M: Waiting in the emergency department. N Z Med J 1996, 109:159-161.

33. Lambe S, Washington DR, Finki A, Laouri M, Lin H, Scuralfose J, Brook RH, Asch SM: Waiting time in Californias emergency departments. Ann Emerg Med 2003, 41:35-44

34. Kyriacou DN, Ricketts V, Dyne PL, McCollough MD, Talan DA: A 5- year time study analysis of emergency department patient care efficiency. Ann Emerg Med 1999, 34:326-335.

35. Huang XM: Patient attitude to waiting in an outpatient clinic and its applications. Health Serv Manage Res 1994, 1994(7):2-8

36. Osmond MH, Brennan-Barnes M, Shephard AL: A 4-year review of severe pediatric trauma in eastern Ontario: a descriptive analysis. $J$ Trauma 2002, $52: 8-12$

37. Cantor RM, Leaming JM: Evaluation and management of pediatric major trauma. Emerg Med Clin North Am 1998, 16:229-256.

38. Marcin JP, Pollack MM: Triage scoring systems, severity of illness measures and mortality prediction models in pediatric trauma. Crit Care Med 2002, 30:5457-S467.

39. Fan- Salek MH, Totten VY, Terezakis SA: Trauma scoring system explained. Emerg Med 1999, 11:155-166.

40. Furnival RA, Schunk JE: ABCs of scoring systems of pediatric trauma. Pediatric Emerg Care 1999, 15:215-222.
41. Monini M, Rezaishiraz H, Zafarghandi MR: Characteristics and outcome of injured patients treated in urban trauma centers in Iran. J Trauma 2000, 48:503-507

42. Advanced life support Group: Advanced pediatric life support; The practical approach. 2nd edition. London: BMJ Publishing Group; 1997.

43. Kang EG, Sharma GK, Lazano R: The global burden of injuries. Am J Public Health 2000, 90:523-526.

44. Muller MJ, Pegg SP, Rule MR: Determinants of death following burn injury. Br J Surg 2001, 88:583-587.

45. Wong MK, Ngom RM: Burn mortality and hospitalization time; a prospective statistical study of 352 patients in an Asian National Burn Centre. Burns 1995, 21:33-46.

46. Osifo $\mathrm{OD}$, Iribhagbe $\mathrm{PE}$, Ugiagbe EE: Epidemiology and pattern of paediatric and adolescent trauma death in a level 1 trauma centre in Benin City, Nigeria. Injury 2011. Aug4 [Epub ahead pf print].

47. Ameh EA, Mshelbwala PM: Challenges of managing paediatric abdominal trauma in a Nigerian setting. Eur J Pediatr Surg 2007, 2:90-95.

48. Bokhari Z, Meier KJ, Msuya D, Lakhoo K: Surgical procedures for trauma in children in Northern Tanzania. Afr J Paedietr Surg 2010, 7:217-239.

doi:10.1186/1752-2897-7-10

Cite this article as: Simon et al: Paediatric injuries at Bugando Medical Centre in Northwestern Tanzania: a prospective review of 150 cases. Journal of Trauma Management \& Outcomes 2013 7:10.

\section{Submit your next manuscript to BioMed Central and take full advantage of:}

- Convenient online submission

- Thorough peer review

- No space constraints or color figure charges

- Immediate publication on acceptance

- Inclusion in PubMed, CAS, Scopus and Google Scholar

- Research which is freely available for redistribution 